\title{
Maximum Power Point Tracking in Solar Power Systems by Using Differential Evolution Methods with Embedded Systems
}

\begin{tabular}{|cc|}
\hline & \\
\hline & Volkan YAMAÇLI ${ }^{1 *}$, Kadir ABACI $^{\mathbf{2}}$ \\
\hline${ }^{1,2}$ Mersin University, Faculty of Engineering, Electrical and Electronics Engineering, Mersin, 33343 Turkey \\
\hline \\
\hline
\end{tabular}

\begin{abstract}
In this paper, one of the most important problems, Maximum Power Point Tracking (MPPT), in renewable solar power is studied and analyzed. In order to obtain the maximum power point in solar cells and panels the voltage and current should be maximized, simultaneously. Thus, the easiest way to achieve the maximum power point is tracking the solar energy, daylight, by measuring the light intensity in a solar cell or panel coaxially. In this work, the MPPT is achieved by optimizing the light intensity vector on a solar panel after measuring the daylight physically with the help of newly designed embedded system, and processing the real world values by using Differential Search Algorithm which is a new and improved method based on differential evolutionary principles.
\end{abstract}

Key Words

"Solar Power, Maximum Power Point Tracking, Renewable Energy, Differential Search, Optimization." 


\section{Introduction}

As electricity plays a vital role in the economy and industrial activity of a country, electric power systems have extensively expanded in the past decades. Electricity is generated in stations, transmitted by high voltage transmission networks, and delivered to consumers. With the ever-growing energy demand, power systems become more complex and difficult to control because the systems are being operated under highly stressed conditions such as unscheduled power flows and higher losses (Abaci et al., 2016). In the recent years, despite the technological progress on science; the problem of lack of energy continues by being much more vital. As the quality and accuracy of mathematical and psychical models of electrical systems improve, renewable technologies become the focus of theoretical and practical studies. In particular, solar energy attracts much attention. The utilization of photovoltaic (PV) conversion energy is today an emerging technology, characterized by gradually declining costs and increasing acquaintance with the technology (Belarbi et al., 2016). An accurate equivalent model of PV devices is an important task for determining and designing optimal PV systems. In total, three different models are required to model the electrical power output of a PV system for given irradiance and ambient temperature. These include a thermal model for finding the PV cell temperature, a radiation model for finding the solar energy absorbed in the PV cells and an electrical model for calculating the electrical characteristics of the PV system for the calculated absorbed radiation and cell temperature. Over the years, electrical models for varied complexities and accuracies have been developed for PV system. These include analytical models based on PV cell physics, empirical models and a few models which combine these two approaches (Siddiqui, 2013). But there is also a difficult task having similar importance with PV modeling, the maximum power point tracking problem. Thus, it is necessary to study MPPT method to extract the maximum power from PV panels. Various algorithms of power tracking are being researched or used in PV application (De Vrito, 2013). Those methods include the constant voltage tracking (CVT), the perturbation and observation algorithm (P\&O), the incremental conductance algorithms (INC), OVC method, IC and IC Based on PI method, System Oscillation and Ripple Correlation, Beta Method, Temperature Method, Fixed Duty Cycle method and artificial intelligence methods such as fuzzy logic method, neural network method (Zhiqianf et al., 2017).

In order to simulate and realize the MPPT behavior and solve the problem, PV cells should be modeled and classified. In literature, the cells are modeled in two basic types which are one diode equivalent model and two diodes equivalent model. The quality and accuracy of a model increase as the number of parameters of the model increase but concerns of mathematical difficulties and simulation duration cause model parameters to be chosen fixed or neglected. There have been various studies on PV cell modeling and parameter estimation. Marion (Marion et al., 2004) determined the current and voltage curves by using interpolation technique while King (King et al., 2004) develops an experimental model for PV devices. Townsend (Townsend, 1989) developed a PV model equivalent circuit model by using four parameters and which neglects and chooses the shunt resistance infinite. Due to the accuracy issues of four parameter model, Beckman (Duffie, 1991) asserted a new model and mathematical solution which is called five parameter model in which the parameters can be defined as $I_{L}, I_{0}, a, R_{s}, R_{s h}$ where shunt resistance is also processed despite causing nonlinearity. Later, new methods are developed for determining the solution set of parameters by using the I-V curve (Desoto et al., 2006) and the five parameter model is improved (Valerio et al., 2010).

Due to nonlinearity of the model, it is not possible to find a definite solution set for both PV model and MPPT numerically. Thus, estimation and optimization methods are used to determine these parameters with the purpose of converging to measured or simulated parameters as soon as possible. There are different methods have been used to estimate the parameters in literature. In some studies nonlinear solver scripts are used to determine the parameters while solving the equations numerically by defining and fixing a parameter in some others (Boyd et al., 2011), (Villavla et al., 2009) or solving the nonlinear equations iteratively with the minimum convergence error (Carrero et al., 2016). In various numerical and heuristic optimization techniques are used to estimate the model parameters for different characteristics of PV cells. Levenberg-Marquardt optimization technique and simplex search algorithm are used in literature recently (Ikegami et al., 2001), (Siddiqui, 2011).

Fuzzy optimization (Chen, 2001), (Lin, 2010) neural network based methods (Chen, 2010), (Chen, 2011) and heuristic methods (Moldovan et al., 2009) are used to determine the model parameters of a PV cell.

Recently, a population based method, differential search algorithm (DSA), which is a new and effective differential evolutionary method based algorithm for solving real-valued numerical optimization problems is presented by Pinar Civicioglu (Civicioglu, 2012). In this paper, a novel DSA-based approach is proposed for the purpose of solving the OPF problem. The main contribution of this paper is determining the MPPT and position of PV panel by using DS algorithm. The accuracy of the estimated parameters by using DS algorithm are compared to simulated base model and results are presented.

\section{PV Cell Modeling}

The equivalent circuit shown in Figure 1 consists of a light generated current source, a p-n junction diode and two resistances. I$\mathrm{V}$ relationship in the equivalent circuit of Figure 1 is expressed by Eq. (1). The characteristic of any PV device are included in the model by five model parameters $\left(\mathrm{I}_{\mathrm{L}}, \mathrm{I}_{0}, \mathrm{a}, \mathrm{R}_{\mathrm{s}}, \mathrm{R}_{\mathrm{sh}}\right)$. The model that describes the electrical performance of a PV device represented by Figure 1 using Eq. (1) is called the five parameter model (Siddiqui, 2013).

$$
I=I_{L}-I_{0}\left(\exp \left(\frac{V+I \cdot R_{S}}{a \cdot V_{T}}\right)-1\right)-\frac{V+I \cdot R_{S}}{R_{S h}} \quad\left(V_{T}=\frac{k \cdot T_{c}}{q}\right)
$$


where q, $\mathrm{k}$ and Tc are elementary charge, Boltzmann's constant and cell temperature, respectively.

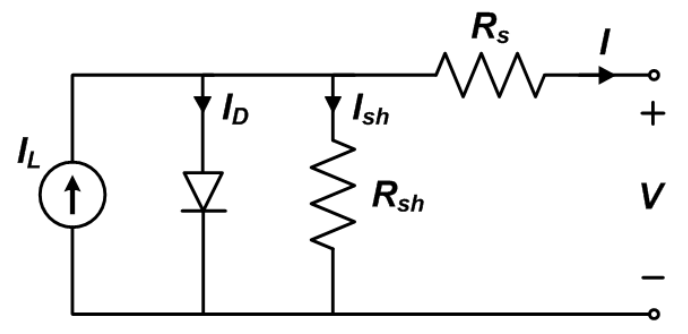

Figure 1: Equivalent circuit of a PV cell (Gray, 2011)

Eqs. (2) - (6) can be used to calculate the parameters in a desired operating condition which is dependent on cell temperature, solar radiation and band-gap energy of the PV material. Thus, the I-V and P-V characteristic of the PV cell can be predicted by using Eq. (1).

$a=a_{\text {ref }}\left(\frac{T_{c}}{T_{\text {ref }}}\right)$

$I_{L}=\frac{S}{S_{r e f}}\left(I_{L, r e f}+\left(T_{c}-T_{r e f}\right)\right.$

$I_{0}=I_{0, r e f}\left(\frac{T_{c}}{T_{r e f}}\right)^{3} \exp \left(\left(N C S \cdot \frac{T_{r e f}}{a_{r e f}}\right)\left(\left(\frac{E g, r e f}{T_{r e f}}\right)-\left(\frac{E g}{T_{c}}\right)\right)\right)$

$R_{s h}=R_{\text {sh }, \text { ref }}\left(\frac{S_{\text {ref }}}{S}\right)$

$R_{s}=R_{s, r e f}$

The notation of ref describes the parameters at standard test conditions (STC) where temperature and solar radiation are $25^{\circ} \mathrm{C}$ and $1000 \mathrm{~W} / \mathrm{m}^{2}$ respectively in general. NCS and $\mathrm{E}_{\mathrm{g}}$ represents the number of cells and band-gap energy, respectively. Eq. (7) can be used to calculate the band-gap energy for a current condition for different values of temperature where $\mathrm{E}_{\mathrm{g}}=1.43 \mathrm{eV}$ for $\mathrm{GaAs}$ type of material (Desoto et al., 2006).

$E_{g}=E_{g, r e f}\left(1-0.0003174\left(\frac{T_{c}}{T_{r e f}}\right)\right)$

\subsection{PV Cell Objective Function}

In order to achieve a valid solution set for the model parameters by using evolutionary methods, the objective function must be described in desired constraints and rules. The objective function namely fitness function is used to calculate and minimize the global error which leads the algorithm to a better solution set in the current space. The objective function, the normalized error function, is given in Eq. (8) below where $\mathrm{m}$ and e subscripts represent modeled and estimated values of variables, respectively.

$n e=a b s\left(\frac{I_{M P, m}-I_{M P, e}}{I_{M P, e}}\right)+a b s\left(\frac{V_{M P, m}-V_{M P, e}}{V_{M P, e}}\right)+a b s\left(\frac{I_{S C, m}-I_{S C, e}}{I_{S C, e}}\right)+a b s\left(\frac{V_{O C, m}-V_{O C, e}}{V_{O C, e}}\right)$

The electrical characteristic of the model is given by Table 1. I-V and P-V curves for the assumed model parameters are given by Figure 2 and Figure 3, respectively. 
Table 1: Electrical characteristics of the PV model

\begin{tabular}{|l|c|}
\hline Characteristic & Value \\
\hline Short circuit current $\left(\mathrm{I}_{\mathrm{sc}}\right)$ & $3.14 \mathrm{~A}$ \\
\hline Open circuit voltage $\left(\mathrm{V}_{\mathrm{oc}}\right)$ & $19.29 \mathrm{~V}$ \\
\hline MPP current $\left(\mathrm{I}_{\mathrm{MP}}\right)$ & $2.83 \mathrm{~A}$ \\
\hline MPP voltage $\left(\mathrm{V}_{\mathrm{MP}}\right)$ & $12.57 \mathrm{~V}$ \\
\hline Number of cells in series (NCS) & $32-$ cells \\
\hline
\end{tabular}

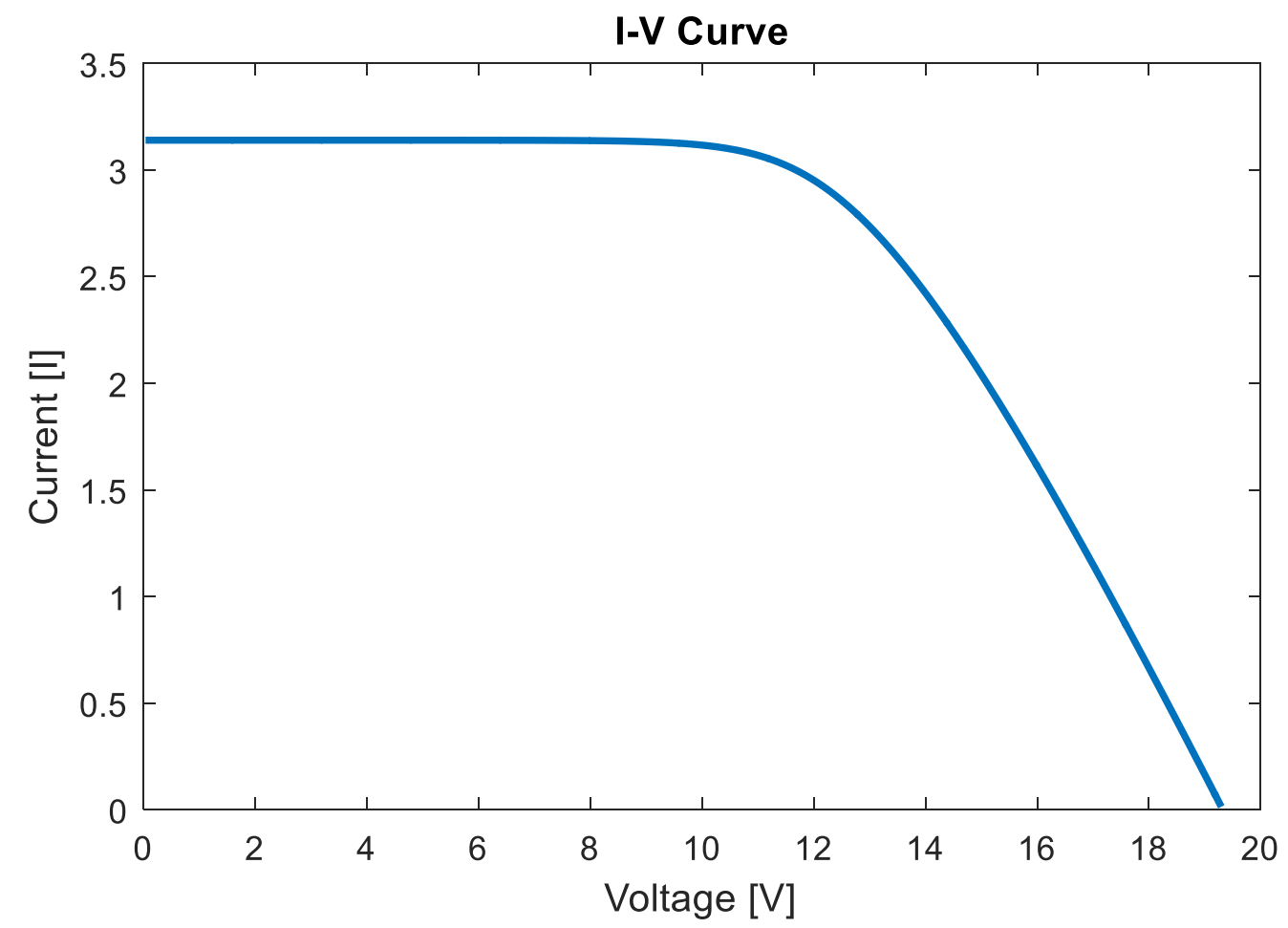

Figure 2: I-V curve for assumed parameters

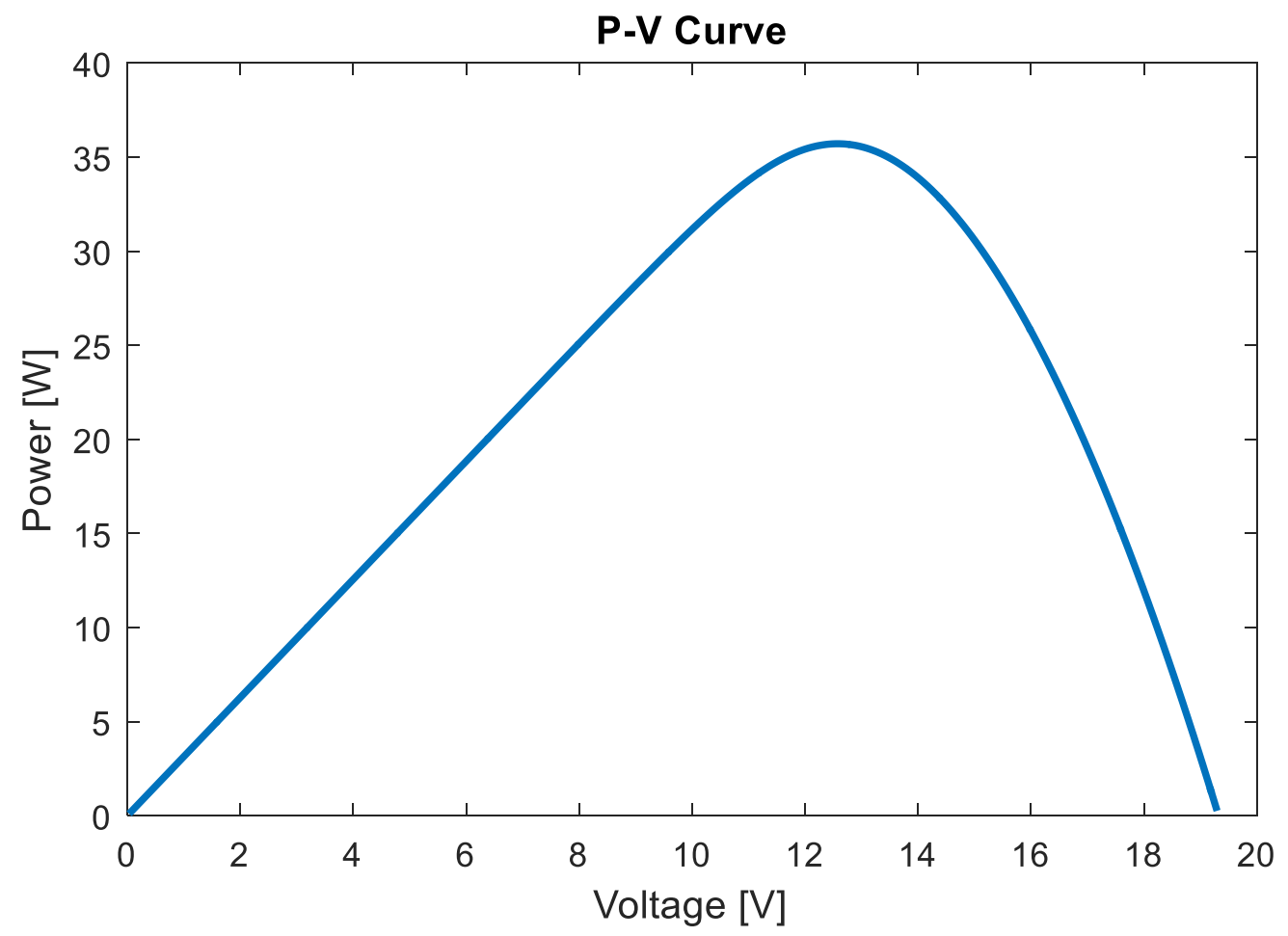

Figure 3: P-V curve for assumed parameters 


\section{Differential Search Algorithm (DS)}

DS is a newly developed optimization algorithm based on differential evolutionary principles which simulates the Brownian-like random-walk movement used by a living organism to migrate.

Quality and efficiency of the food sources in the nature such as meadows and lakes may vary because of the climatic changes during a year, decade or century. In order to find high quality food sources and overcome the famine, living organisms migrates seasonally through intervals. This behavior assures the organism move to a new environment where the food source is of a high quality and variation.

The migrating organisms form a super organism which comprises large number of individuals, and the superorganism starts to change its location by moving to areas containing high quality food sources. Movement of a super organism can be described by a Brownian-like random-walk model. The behavior of superorganisms has been modeled using a number of computational intelligence algorithms, such as PSO, cuckoo search, ant colony, and artificial bee colony. Many species of predatory living beings, before moving or migrating to a site, control the fertility of this one. In other words, if a superorganism desires to move to a new site that can meet its needs, this superorganism settles in this new site at least for a period of time. However, if a more fertile area is found, the superorganism continues its migration (Civicioglu, 2012).

It is assumed, in DS algorithm, that a population made up of random solutions of the respective problem corresponds to an artificialsuperorganism migrating. In DS algorithm, artificial-superorganism migrates to global minimum value of the problem. During this migration, the artificial-superorganism tests whether some randomly selected positions are suitable temporarily during the migration. If such a position tested is suitable to stop over for a temporary time during the migration, the members of the artificialsuperorganism that made such discovery immediately settle at the discovered position and continue their migration from this position on (Civicioglu, 2012).

The pseudo-code indicating the DS algorithm is given by Figure 4, where $\mathrm{N}$ is the population size, $\mathrm{D}$ is the dimension of the problem and $\mathrm{G}$ is the maximum number of generation.

As shown in the formulation above, the DS algorithm employs multiple random numbers in order to generate new artificial organisms and select artificial organisms randomly for the purpose of converging to global optimum. Primarily, there are 4 numbers; randg, rand1, rand2, rand3 randomly generated in each iteration which are used to generate new artificial organisms. Also, there are 6 randomly generated numbers; rand6, rand7, rand8 rand9, rand10 are used in the process of random selection. Thus, the processes aforementioned lead the algorithm to diverge from local minimum and search for possible global optimum meanwhile keeping the variables in constraints (Abaci \& Yamacli, 2016). 


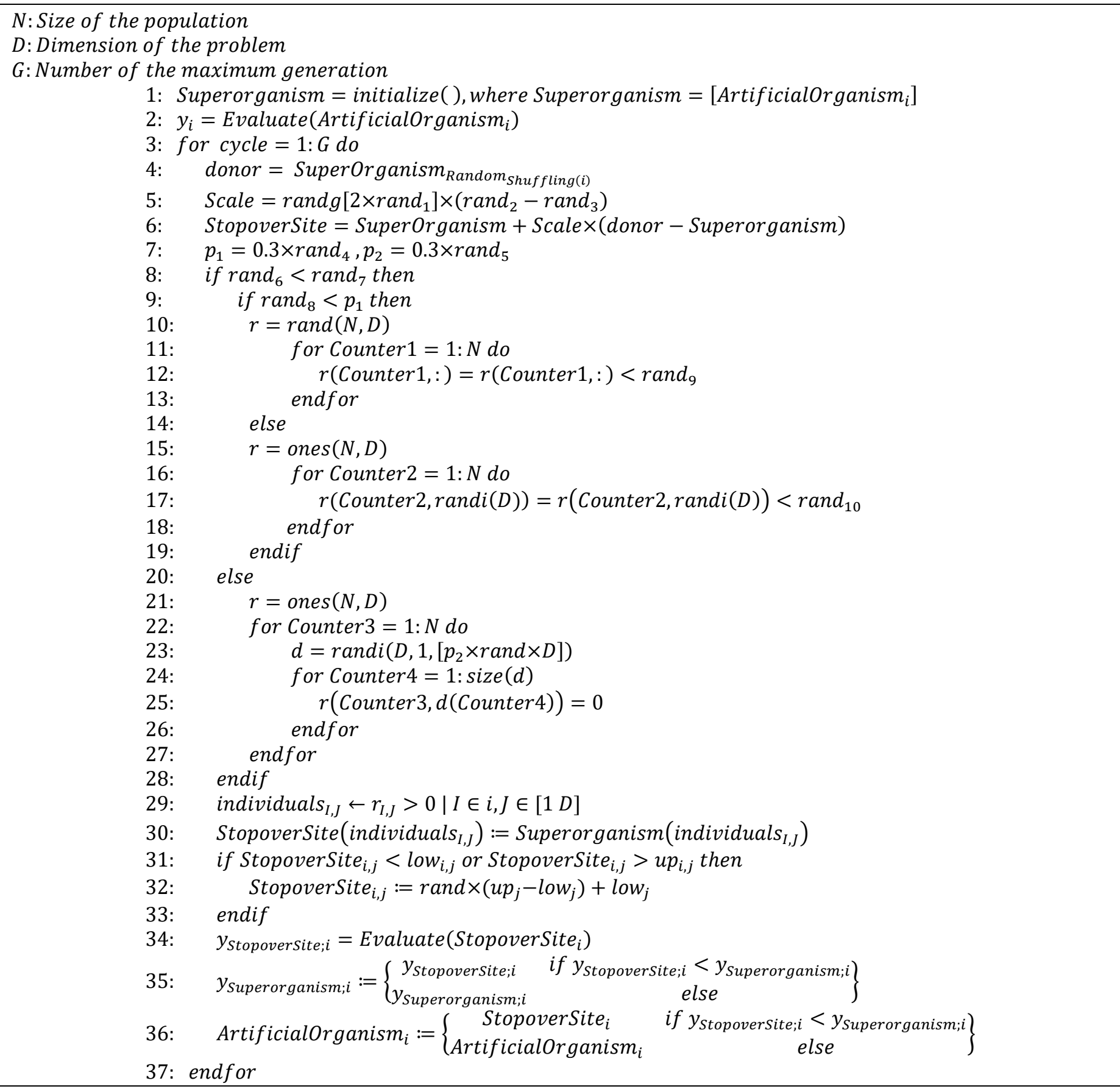

Figure 4: Pseudo-code of DS algorithm

\subsection{DSA Implementation}

DSA is similar to those other population based heuristic methods which use randomly generated possible solution sets of predetermined dimensions (D) in upper and lower constraints. In DSA, N number of artificial organisms composed of D components determined initially forms a super organism. The super organism represents the candidate solution sets consist of PV cell parameters such as $\mathrm{I}_{\mathrm{L}}, \mathrm{I}_{0}, \mathrm{a}, \mathrm{R}_{\mathrm{s}}, \mathrm{R}_{\mathrm{sh}}$. The fitness values of each solution set are calculated and determined by applying the objective function given by Eq. (8).

Stopover site, which contributes the migration motion of artificial organisms, is generated among an artificial organism and a randomly selected donor based on Brownian-like random walk model during the DSA process. It is worthwhile to note that stopover site is generated by using a scale factor which can be a pre-determined fixed value as well as a randomly generated number. This scale factor lets the current artificial organism move and change direction in its constrained D dimensional space based on the size and direction of donor. The stopover site is chosen and replaces the direction of current artificial organism with the condition of 
having a better fitness and also necessitated being in the upper and lower constraints aforementioned. Thus, a new migration motion in $\mathrm{D}$ dimensional space is formed spontaneously in each iteration by determining the best solution set which leads the super organism to the global optimal solution.

For the purpose of using the proposed DSA method for parameter estimation problem can be summarized as;

1. Load the system data and constraints.

2. Specify the DSA parameters such as number of individuals and maximum cycle.

3. Initialize a superorganism consisting a number of solution sets (individuals) for the first iteration.

5. Evaluate the fitness of the results, determine the best individual within the superorganism.

6. Generate new individuals depending on the best individual of the previous iteration

7. Increase cycle number by 1 .

8. $\quad$ Evaluate the fitness value of newly produced superorganism.

9. Memorize the best global solution found so far.

10. Check if the maximum cycle met; stop the iteration process or jump to step 5.

\section{Solar Power and Embedded Systems}

In order to achieve both simulation and realization of MPPT problem, the solar panel and embedded systems are designed by using $2.4 \mathrm{GHz}$ wireless transceiver modules (nRF24L01+) on embedded board which is chosen as Arduino Uno R3. The light dependent resistors (LDR) placed on each corner of solar panel, which has dimensions of 29x19 inches, and the light intensity is measured through analog outputs of LDR modules.

The solar power system can be divided in 2 sub-systems; The field system, which is namely transmitter system, contains solar panel, LDR modules, embedded development board and $2.4 \mathrm{GHz}$ transceiver module. The diagram of first system is shown in Figure 5 .

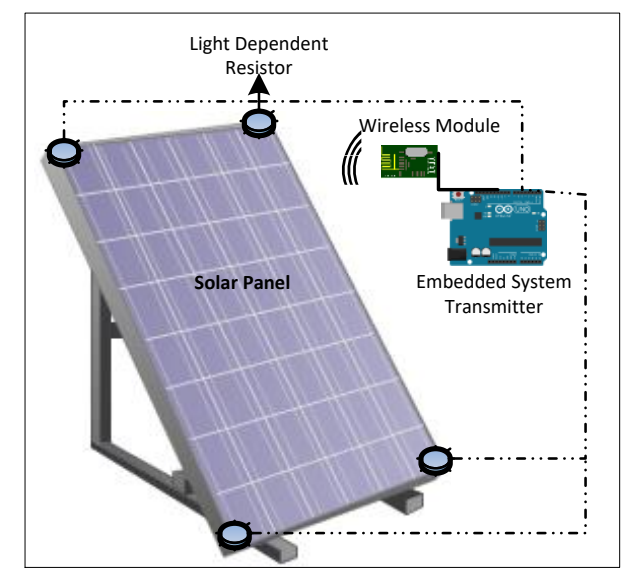

Figure 5: Transmitter field module of the MPPT system

The second system is designed as a receiver computer system, containing a $2.4 \mathrm{GHz}$ transceiver module, embedded development board which is connected to a computer via USB protocol and MATLAB software. Receiver system diagram is shown in Figure 6.

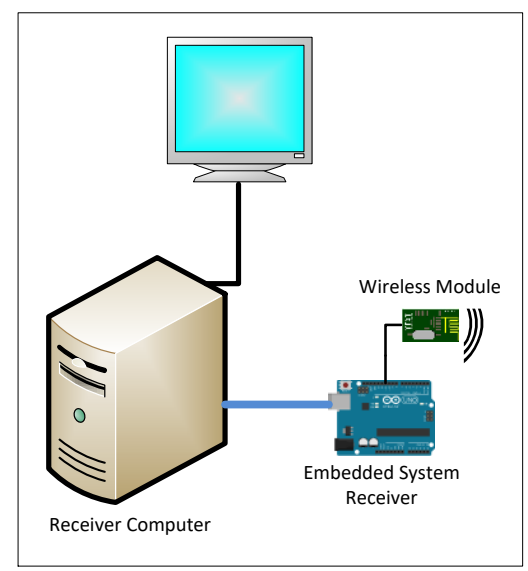

Figure 6: Receiver and computation module of the MPPT system 
The embedded transmitter system code is shown if Figure 7. It is seen that the sensor values of LDRs are measured and sent through the $2.4 \mathrm{GHz}$ wireless transmitter module.

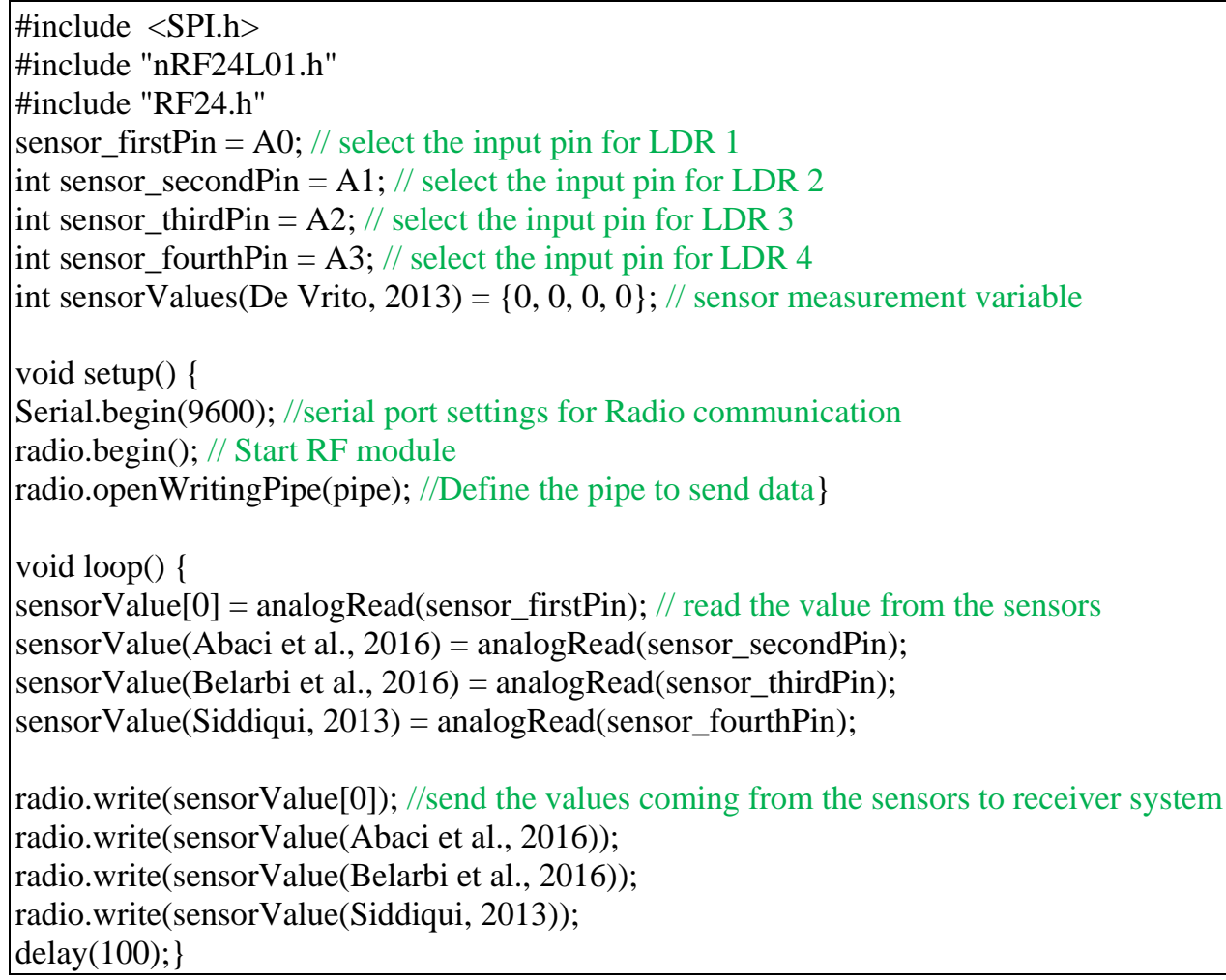

Figure 7: Embedded transmitter system code

Embedded receiver system code is shown in Figure 8. The receiver system reads the data by using wireless module and sends the same data to computer by serial communication protocol in order to process and optimize the values. So the MPPT optimization can be achieved by using the modeled PV panel and the light intensity vector by which is obtained with $2.4 \mathrm{GHz}$ embedded transceiver modules.

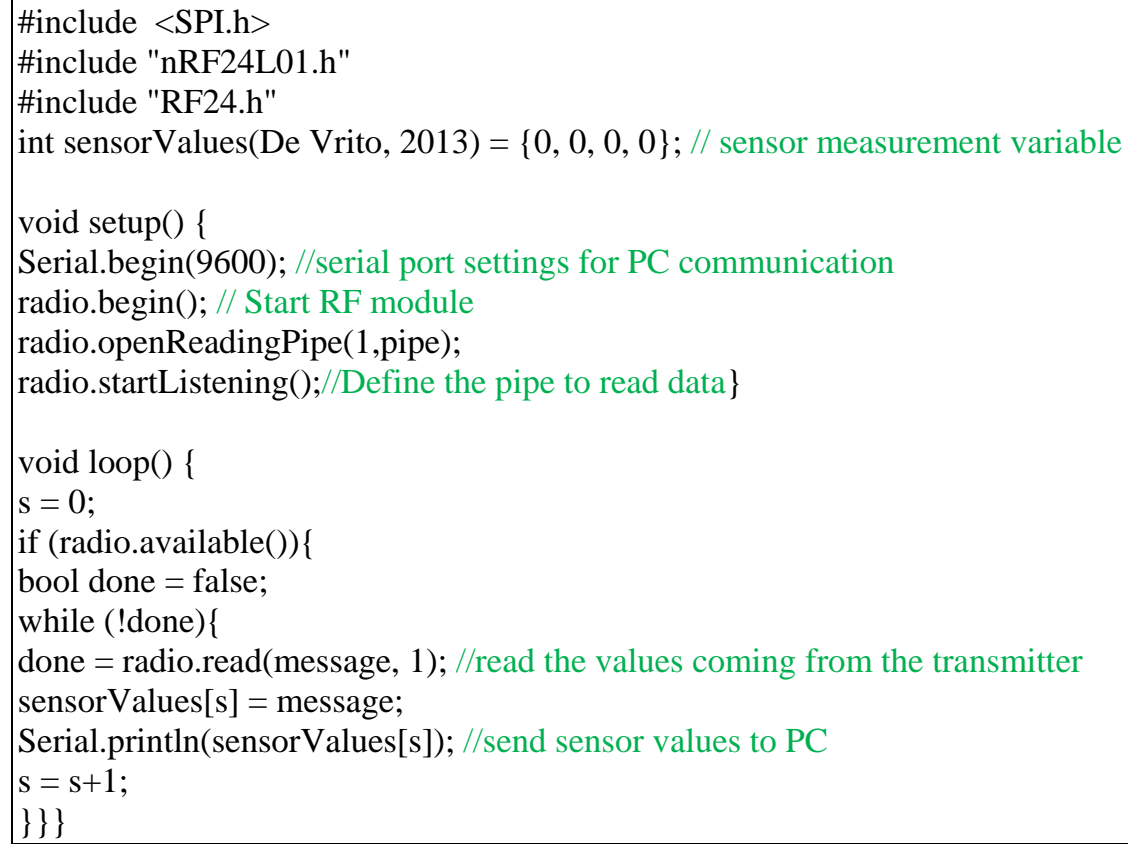

Figure 8: Embedded receiver system code 
Thus, the optimization process continues for defined time ranges while receiver system gets the LDR values to computer continuously. The flowchart of the complete system is given by Figure 9. In the figure below, it can be seen that the receiver component optimizes system parameters by using the light intensity values obtained by transmitter module in order to optimize the solar panel model assumed in Section 2.

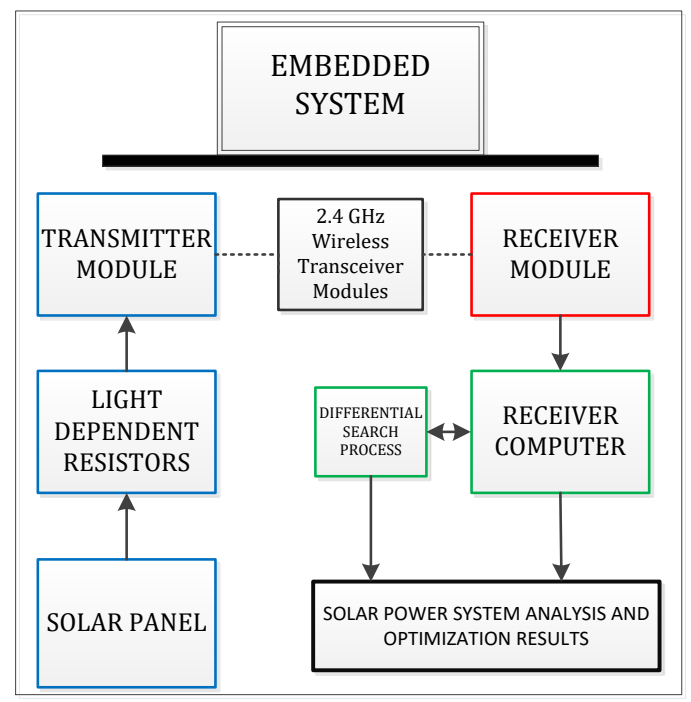

Figure 9: System flowchart

\section{Results and Discussion}

In order to estimate the parameters and optimize the system, the assumed parameters given by Table 1 are searched in 5dimensional space consisting of these variables by using DS algorithm. The fitness values for each iteration are calculated and new super organisms are produced with the purpose of converging the global normalized error, given by Eq. (8), to zero. In addition, with measuring and sampling the light intensity vector obtained by embedded systems, the optimal position of the solar panel and the best light intensity vector for designed system is obtained when the maximum power point is achieved.

In parameter estimation process, the upper and lower values of parameters are limited. Constraints and limit values of five parameter model are given by Table 2 below. If the parameter value violates the upper or lower limit, the upper or lower limit value is assigned as the new parameter value respectively.

Table 2: Electrical characteristics of the PV model optimized to obtain maximum power point

\begin{tabular}{|l|c|}
\hline Parameter & Value \\
\hline Short circuit current $\left(\mathrm{I}_{\mathrm{sc}}\right)$ & $3.18 \mathrm{~A}$ \\
\hline Open circuit voltage $\left(\mathrm{V}_{\mathrm{oc}}\right)$ & $17.49 \mathrm{~V}$ \\
\hline MPP current $\left(\mathrm{I}_{\mathrm{MP}}\right)$ & $2.87 \mathrm{~A}$ \\
\hline MPP voltage $\left(\mathrm{V}_{\mathrm{MP}}\right)$ & $12.53 \mathrm{~V}$ \\
\hline Number of cells in series $(\mathrm{NCS})$ & 32 -cells \\
\hline
\end{tabular}

The I-V and P-V curves for assumed and estimated parameter values of series connected PV cells are given by Figure 7 and Figure 8 , respectively. It can be stated that the calculated Voc value by using the estimated parameters is $17.49 \mathrm{~V}$ while it is $19.29 \mathrm{~V}$ in the assumed model. The power at maximum power point is $35.96 \mathrm{~W}$ for estimated parameter while same variable is $35.57 \mathrm{~W}$ in the assumed model. The I-V and P-V curves of the realized PV model are shown in Figures 10 and 11, respectively. 


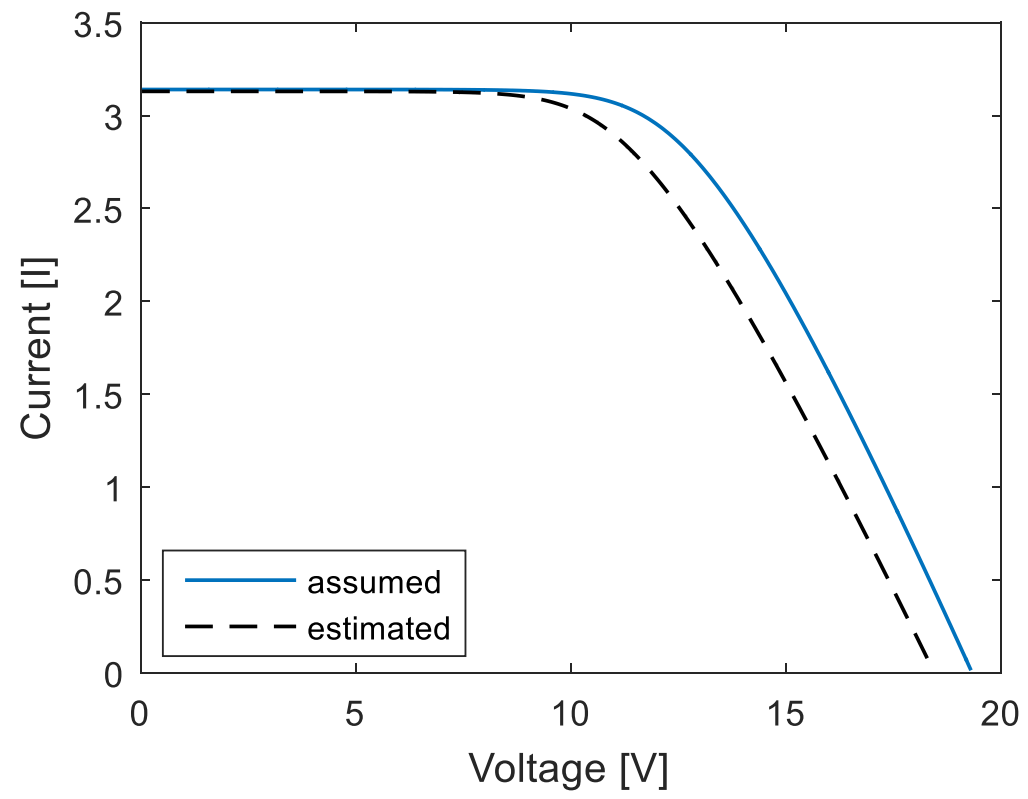

Figure 10: Figure 7: I-V curve of series PV cell for assumed and estimated parameters

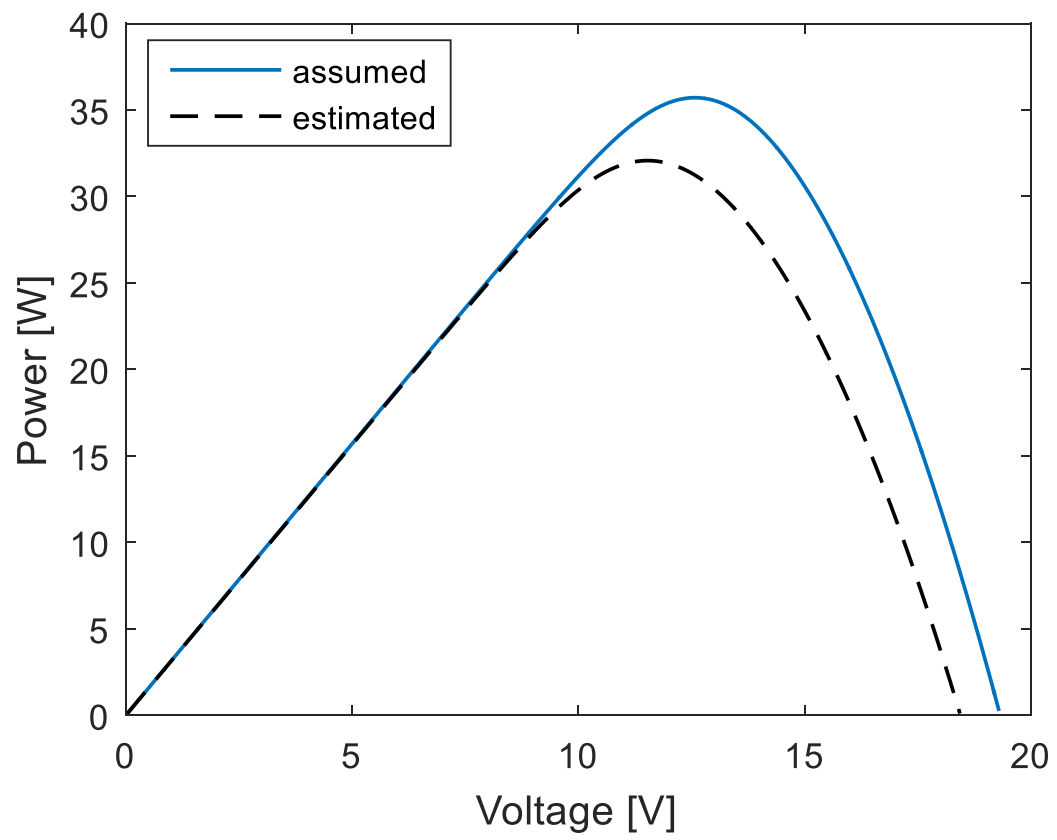

Figure 11: P-V curve of series PV cell for assumed and estimated parameters

\section{Conclusions}

In this paper a differential evolution based optimization method, DSA, is proposed and successfully applied to solve a multi objective function within the constraints regarding to solar cell modeling and maximum power point tracking problem. The results obtained by using the proposed DSA method, which are presented in detail, are compared with assumed model and maximum power point in paper and the efficiency of the DSA is demonstrated. Thus it is concluded that DSA provides a good solution performance, robustness and superiority and can effectively be used in large scaled, non-linear and non-convex problems in parameter estimation and maximum power point tracking area owing to its high solution quality and rapid convergence speed. 


\section{References}

Abaci, K., Yamacli, V., Akdagli, A. (2016). Optimal power flow with svc devices by using the artifcial bee colony algorithm. Turkish Journal of Electrical Engineering \& Computer Sciences, 24, 341-353.

Abaci, K., Yamacli, V. (2016). Differential search algorithm for solving multi-objective optimal power flow problem. International Journal of Electrical Power \& Energy Systems, 79, 1-10.

Belarbi, M., Boudghene, A., Belarbi, E.H., Haddouche, K. (2016). A new algorithm of parameter estimation of a photovoltaic solar panel. Turkish Journal of Electrical Engineering \& Computer Sciences, 24, 276-284.

Boyd, M.T., Klein, S.A., Reindl, D.T., Dougherty, B.P. (2011). Evaluation and validation of equivalent circuit photovoltaic solar cell performance models. Journal of Solar Energy Engineering, 133(2), 1-13.

Carrero, C., Ramírez, D., Rodríguez, J. Platero, C.A. (2016). Accurate and fast convergence method for parameter estimation of pv generators based on three main points of the I-V curve. Renewable Energy, 36(11), 2972-2977.

Chen C.W. (2001). A fuzzy ahp-based fault diagnosis for semiconductor lithography process", International Journal of Innovative Computing. Information and Control, 7(2), 805-816.

Chen C.W. (2001). Fuzzy control of interconnected structural systems using the fuzzy Lyapunov method. Journal of Vibration and Control, 17(11), 1693-1702.

Chen C.W. (2010). GA-based adaptive neural network controllers for nonlinear systems. International Journal of Innovative Computing, 6(4), 1793-1803.

Chen C.W. (2011). Stabilization of adaptive neural network controllers for nonlinear structural systems using a singular perturbation approach. Journal of Vibration and Control, 17(8), 1241-1252.

Civicioglu P. (2012). Transforming geocentric cartesian coordinates to geodetic coordinates by using differential search algorithm. Computers \& Geosciences, 46, 229-247.

De Brito, M.A.G., Galotto, L., Sampaio, L.P., de Azevedo e Melo, G., Canesin, C.A. (2013). Evaluation of the main MPPT techniques for photovoltaic applications. IEEE Transactions on Industrial Electronics. 60(3), 1156-1167.

Desoto, W., Klein, S.A., Beckman, W.A. (2006). Improvement and validation of a model for photovoltaic array performance. Solar Energy, 80, 78-88.

Duffie, J.A., \& Beckman, W.A. (1991). Solar engineering of thermal processes (2nd ed.). New York, John Wiley \& Sons.

Gray, J.L. (2011). The physics of the solar cell, in handbook of photovoltaic science and engineering. New York, John Wiley \& Sons.

Ikegami, T., Maezono, T., Nakanishi, F., Yamagata, Y., Ebihara K. (2001). Estimation of equivalent circuit parameters of pv module and its application to optimal operation of pv system. Solar Energy Materials and Solar Cells, 67, 389-395.

King, D.L., Boyson W.E., Kratochvil J.A. (2004). Photovoltaic array performance model. Sandia National Laboratories, Albuquerque, NM.

Lin M.L. (2010). Application of fuzzy models for the monitoring of ecologically sensitive ecosystems in a dynamic semi-arid landscape from satellite imagery. Engineering Computations, 27(1), 5-19.

Moldovan, N., Picos, R., Garcia-Moreno, E. (2009). Parameter extraction of a solar cell compact model using genetic algorithms. Spanish Conference on Electron Devices Proceedings, 379-382.

Marion B., Rummel S., Anderberg A. (2004). Current-voltage curve translation by bilinear interpolation. Progress in Photovoltaics, $12,593-607$.

Siddiqui, M.U. (2011). Multiphysics modeling of photovoltaic panels and arrays with auxiliary thermal collectors, MSc Thesis, King Fahd University of Petroleum \& Minerals, Saudi Arabia. 
Siddiqui, M.U., Abido, M. (2013). Parameter optimization for five- and seven-parameter photovoltaic electrical models using evolutionary algorithms. Applied Soft Computing, 13(12), 4608-4621.

Valerio, L.B., Orioli, A., Ciulla, G., Di Gangi, A. (2010). An improved five-parameter model for photovoltaic modules. Solar Energy Materials and Solar Cells, 94(8), 1358-1370.

Villalva, M.G., Gazoli, J.R., Filho, E.R. (2009). Comprehensive approach to modeling and simulation of photovoltaic arrays. IEEE Transactions On Power Electronics. 24(5), 1198-1208.

Townsend, T.U. (1989). A method for predicting the long-term performance of directly-coupled photovoltaic systems, MSc thesis, University of Wisconsin, Madison

Zhiqiang Gao, Song L., Xuesong Z., Youjie M., Jian Z. (2017). A new maximum power point tracking method for pv system. $29^{\text {th }}$ Chinese Control And Decision Conference Proceedings, 544-548. 